\title{
THE DEVELOPMENT OF SUSTAINABLE ECOTOURISM IN PROTECTED AREA, CASE STUDY: SIWA OASIS
}

\author{
M. TAWFIK \\ Department of Architecture, Higher Institute of Engineering, El-Shorouk Academy, Cairo, Egypt.
}

\begin{abstract}
The objective of this study is to present a coherent theoretical framework to deepen the essence of sustainable design and to reach an explanation for its constituent components in the environment of a protected area. This study examines the physical changes of protected areas and the acts of improvement made so that there will be fewer damages to the local environment. Reaching a sustainable framework would contribute to the protection of these areas and the environment in general. To achieve this objective, the ideas of 'sustainable development' and 'sustainable ecotourism' have been studied. The next step is concerned with the outcome of these studies; in addition a model called 'sustainable design to Locator' has been recommended to set up a theoretical framework for the main items in the design of a sustainable protected area. The final step is the fundamental assumptions, strategies and plans related to the subject; qualitative results based on functional, environmental, experimental and aesthetic items have been reached.

Keywords: ecotourism, protected area, sustainability sustainable design to locator, sustainable development, sustainable structure.
\end{abstract}

\section{INTRODUCTION}

From the past experience that I gained while studying the protected areas in Egypt, it came to light that the development in these areas were an absolute failure in accomplishing required development goals in Egypt's protected areas. It seems that if the country's policies and programs regarding the intrusion on these protected areas in Egypt, and the absence of appropriate organizations that take responsibility for these areas, there won't be a chance in building protected areas that accomplish the protected goals. Therefore, it's extremely important to study the sustainable designs. There are also other important factors that we should take in to consideration and study them and these factors are the economical, the social, the physical and the human aspect as well. In order to reach the maximum level of protection a development in Siwa's protected area. The residents need to have simple knowledge considering the area. In order to do that we should study their way of behavior and their knowledge considering the protected area. You can ensure the protected areas safety and development by ensuring that its residents are fully aware of its importance and how to deal with it and by that the percentage of development will be raised. This will lead that the maximum sustainable development can be ensured. This will reflect on the area's economic, financial, and physical aspects. This goal will be reached by talking to the residents of the Siwa's protected area.

The physical aspects of a protected area reflect social, economic, and environment aspects [1]. Therefore, recommendations for living in a protected area may include: \footnotetext{
This paper is part of the Proceedings of the $7^{\text {th }}$ International Conference on Sustainable Tourism
(Sustainable Tourism 2016)

CONFERENCES www.witconferences.com
} 
- Accurate recognition of a protected area's problems is very important as these problems prevent societies from developing.

- The changes made to the protected area such as buildings, streets, facilities and leading industries are formal elements that hold space.

- The natural, cultural, economic, and social structures (especially the geographical environment) have internal organization and special skeletal structures that affect housing and 'native outlook' [2].

- The protected area native outlook in Egypt in terms of the nature of its function and its relation to human needs, activities, production elements, and the environment forms an equal set with a special nature that represents connections, functions, and a multifunctional role of spaces.

- In addition to rapid technology advancement, The modern systems can be increased by protecting the native outlook and its unique aesthetic qualities in order to promote worthy culture in protected areas and increase modernity and culture bases [3].

- In addition to protecting quality, diversity and different environments, sustainable tourism seeks to promote the social level of both the people living on a protected area and striking a balance between them and tourism in their location. Thirty years ago, many countries began focusing on protecting the natural and human environments and available diversity.

- These efforts have been categorized under development and protection creating sustainable development rules, and new options in sustainable tourism such as 'Sustainable Ecotourism'.

\section{TERM DEFINITIONS}

Sustainable Ecotourism: Since 'ecotourism' is a new expression, its meaning and its significance are often in question. Hector Ceballos-Lascurain used this expression for the first time in 1988 in Mexico. He said that ecotourism is a form of tourism with the objective of observing and studying nature, wildlife and different cultures, in addition to relaxing in the natural environment. Therefore, ecotourism can be considered a product of sustainable development [4].

Sustainable ecotourism is sustainable as an ecological anthropology [5]; meaning that it can be an answer to take current needs (Social, political, economic, and cultural) of ecologies. Instead of destroying nature, it helps protect and increase opportunities for the continuation of life in the future (ecological stability). Sedler is one of the first to discuss the model of ecotourism in 1990. It includes social, economic, and environmental goals, which consist of providing social benefits, teaching and jobs for the locals. Economic aims consist of economic benefits for the local host society and economic stability, while environmental aims consist of helping to protect the native outlook as it is the main element that forms protected area structures and shows quality of economy, geography, and climate influence and quality of culture, traditions, and people activities. Respecting both basic types is hidden in the nature of the native outlook. The first is the connection to the cultural environment, considering all of its values and rules; while the second is the connection to the natural environment considering the data given to humans by nature [1].

Based on Butler's definition, sustainable tourism is a type of tourism that runs in an environment for an unlimited period of time without damaging the environment or facilitates for sustainable development, and does not interfere with other social activities and processes [6]). Based on the definition by the Australian Tourist Commission (ATC), sustainable tourism is the natural resources of the location, avoiding the destruction of such resources and the management of the supply and demand of such resources. Finally, a combination of these aims is called as 'sustainable ecotourism'. 
Ecotourism is a means of protecting natural resources. Economical use of natural scenery and providing enough budgets to protect them are possible as a result of an increase and development in ecotourism [4] Areas fit for ecotourism in Egypt are widespread but mostly unregistered and on the verge of destruction. Geographical reviews and feasibility studies on ecological anthropology state that ecotourism is a rare, special, and abandoned economic resource that is worthy of investment.

Ecotourism is one of the most promising ways for protected areas to generate tangible and sustainable benefits from nature-based tourism. It can provide a meaningful incentive and economic justification for conservation as it depends on the maintenance of unspoiled nature and thriving communities of wild plants and animals. In addition, it can generate an influential and articulate clientele who can serve as advocates for the conservation of protected areas. However, if it is not managed carefully, nature-based tourism tends to degrade the very resources upon which it depends, which has been happening in the region [7]. According to the World Tourism Organization (WTO), one of five major tourism trends will be a significant growth in adventure tourism and in ecotourism. The WTO forecasts solid growth in cultural tourism; the Middle East and North Africa (MENA) region is among those where such degradation is expected to happen in the near future [8]. It is, therefore, critical that tourism be carefully planned to ensure that such developments and activities do not compromise the natural and cultural values for which protected areas were established in the first place. This can only be ensured through effective management of these areas. Development of strong partnerships between protected area agencies and tourism agencies, including commercial operators, must be emphasized [7].

\section{SIWA OASIS A HISTORICAL NATURAL OASIS}

The Siwa Oasis protected area has been selected as the case study for this research. Reasons for its selection include its cultural, historical, and natural importance along with the unique forms of its houses, which represent an organic architecture with rocks. Having a close relationship between protected area architecture and the surrounding natural environment is one of the biggest factors in attracting tourists. In the future, this attraction can be upgraded from its national and regional level to an international level. The 7000-year-old Siwa Oasis is located in the Egyptian western desert. It is about 300 kilometers from the Mediterranean coast to the southwest of Marsa Matrouh. It boasts the area of 'Shali' with its ancient castle, pharaonic temple and many other sanctuaries, Fig. 1. The Oasis' average land level is 18 meters below the sea surface. Its urban town of Siwa is inhabited by approximately 60,000 people. In 2014, the oldest traces of human footprints were discovered dating back 3 million years [9].

Due to the beautiful weather of this area, the soil around Siwa has been fertilized resulting in many desirable farming lands. The economy of Siwa depends on agriculture and handcrafts, [6] Fig. 2. The main reason for choosing Siwa is its specific architecture from the native outlook of that area as it plays an important role in the architecture of the Oasis. This rare architecture shows the relation between humanity and nature. The distinct outlook of Siwa is a simple pattern combining nature and geography that meet people's basic needs despite having economic and cultural activities that are different from other parts in Egypt. The most important point of the architecture in Siwa Oasis can be observed by making space and structures, (taper-shaped rocks), Fig. 3. The Siwan people try to make use of the smallest of spaces, agricultural fields, water resources (Siwa wells), and life safety. Nowadays, tourism as an economic, social and cultural activity has an important role in developing areas. The strategic positioning and topography are the main reasons for the stability and persistency of the Siwa Oasis. 


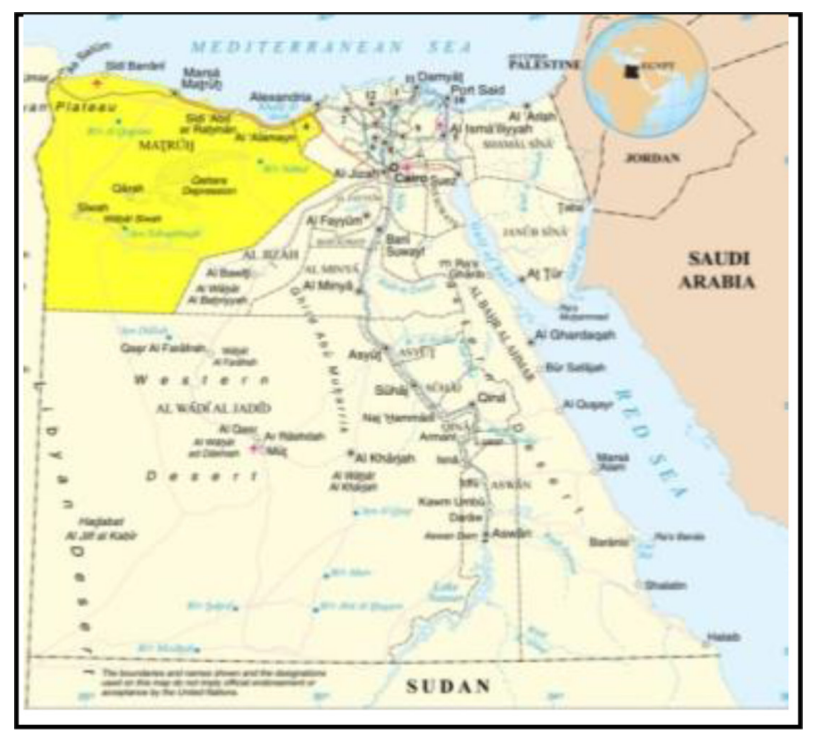

Figure 1: Egypt map.

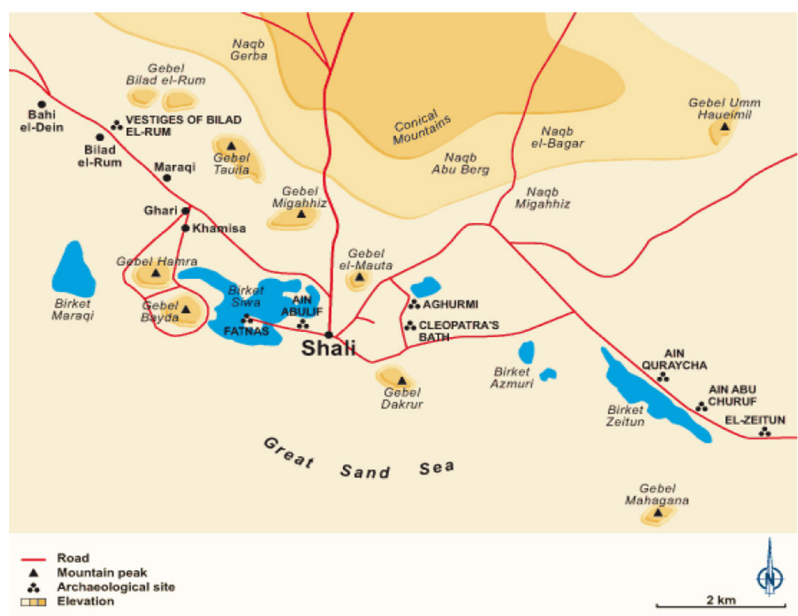

Figure 2: Siwa Oasis map.

The reasons of interest in new architecture can be summarized as: Damp and small spaces caused the people of Siwa Oasis to resort to new structures in order to make money and Siwans usually use ground floors to keep their animals and live on the first and second floors. According to tourism statistics, the number of tourists both local and foreign that visited Siwa between 2008 and 2010 were around 400,000 tourists. They stayed less than two days in the Oasis during the period from October to April, which is the high season for the Oasis, Fig. 4.

- In recent years, Siwa Natural Hotel raised the number of tourists. But because of the views of their society, the Oasis locals view tourists as 'intruders' 


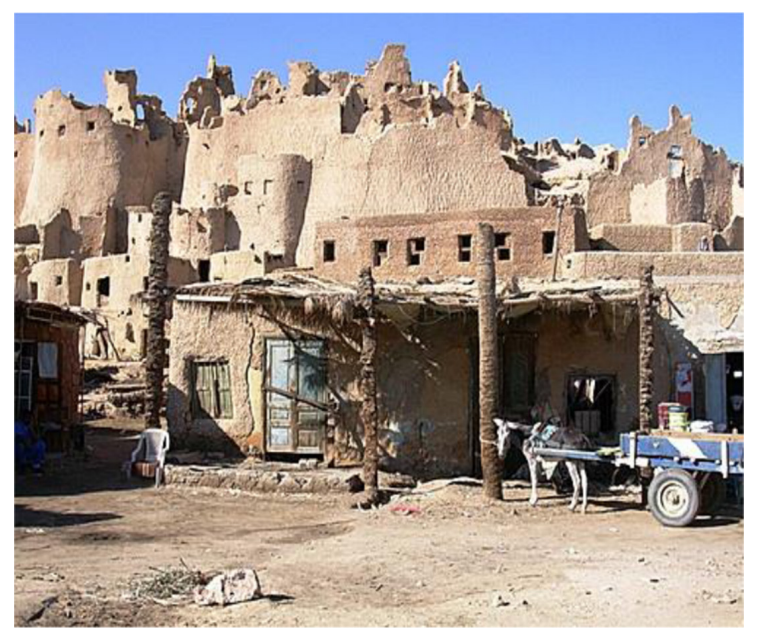

Figure 3: The ruins of Shali city where they used 'Kershef' building material as a fundamental material in construction.

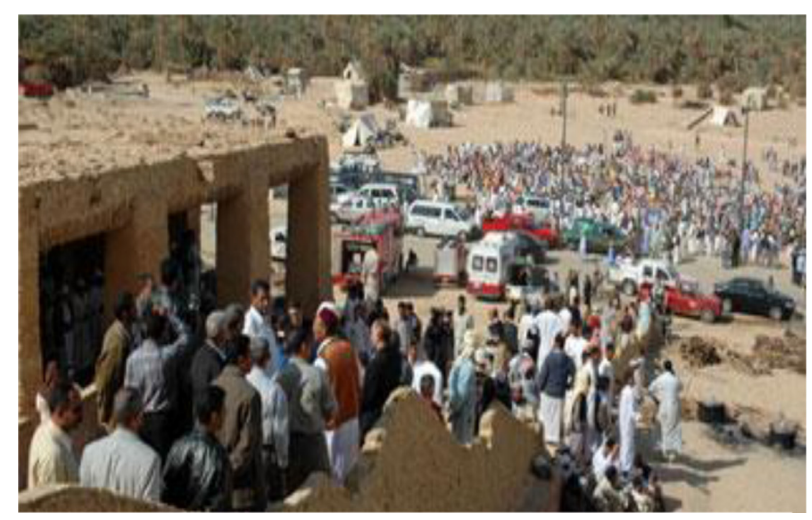

Figure 4: shows 30,000 tourists on holiday in the Oasis.

- Fundamental Assumptions and Sustainable Ecotourism Ideals in Siwa:

- Protecting the natural environment and ecological anthropology of Siwa Oasis.

- Slow growth and controlled tourism

- Determining tourism capacity

- Creating an outline for the development of tourism that is compatible with the environment, economy and culture of the Oasis.

- Connecting tourism with other parts of the local economy to create work.

- Accurate and planned marketing for tourism.

- Providing facilities for old people in the Oasis.

- Teaching Oasis natives in order to protect and improve their native culture.

- Conducting general researches in all subjects related to the Oasis and its people. 


\section{PROBLEMS IN THE OASIS}

In addition to the problem of desertification facing the Oasis [9], there are problems in vehicles, water resources due to increased agricultural activity and land reclamation, which attracted investors from outside the Oasis, encouraged by the government, added to the bottling water industry, where there are five factories in the vicinity of the Oasis. On the other hand, due to increased water consumption, the Oasis suffers from a deteriorating drainage system leading to the salinization of land and the emergence of a large lake of wastewater not suitable for drinking and agriculture. The Oasis has other problems, some linked to biodiversity due to human activity, whether local or resulting from tourism, others related to farmers seeking to commercialize cultivation. There are also problems related to the cultural identity of the inhabitants of the Oasis' as over its history, the society became a closed and isolated one with its own social customs and traditions; however, recent openness due to tourism resulted in changes in prevailing behavioral patterns among the new generations, such as the phenomenon of child beggars, which was not present before.

Siwa hosts several long-standing tribes, namely the Amazigh people who reside in the eastern side of Siwa and who have long maintained their traditions, customs and language (Tasuji, which is one of the Amazigh dialects). They do speak Egyptian Arabic alongside their own dialect. It is said that the Amazigh population in Egypt ranges from 21,000 to 25,000 people, divided on 10 tribes. Some tribes have come from Algeria, others from Morocco, and the others immigrated to Siwa at the time of the Pharaohs [9].

\section{MAIN ITEMS OF SUSTAINABLE DESIGN BASED ON A SUSTAINABLE LOCATION}

Theorists of sustainable design assume that it is a 'phenomenon' or 'event' that each group of oasis natives living in a particular territory with its defined boundaries has specific natural faults. It is worth noting that the suggested styles of civil design that have been discussed in this research are suitable for smaller areas like oases, and that their outcomes can be optimized in the Oasis, formed in the way of two-sided interaction between formal and tangible properties on one hand, and patterns and culture secrets on the other [10]. Therefore, current research suggests a 'sustainable design to Siwa Oasis' model that spots new ecological theories and their stability framework.

This model can be used as basis for a theory to recognize components of sustainable design in oasis areas. Accordingly, it is possible to deduce that combining sustainable design forces from each pair of dimensions (form, activity, visions, and ecology) of the three-item model that includes the practical components (form + activity), experimental-aesthetic components (activities + visions), and environmental components (form + ecology).In general, the three-component model suggested in this research has all the necessary universality to
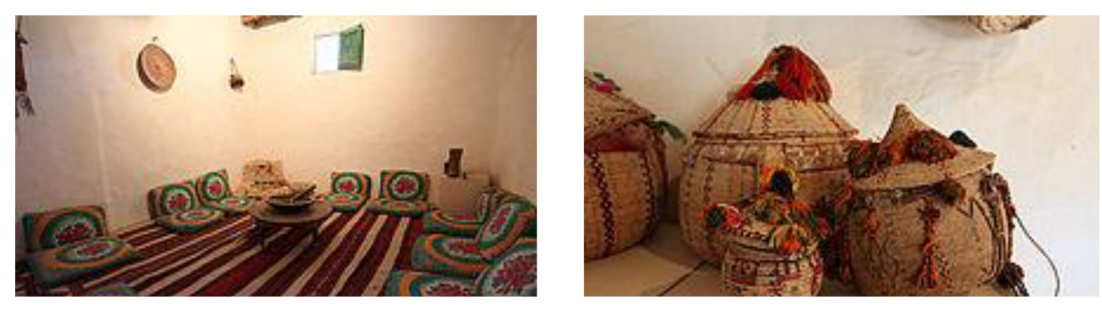

Figure 5: The distinctive heritage and handmade crafts of the people of Siwa Oasis [12] 

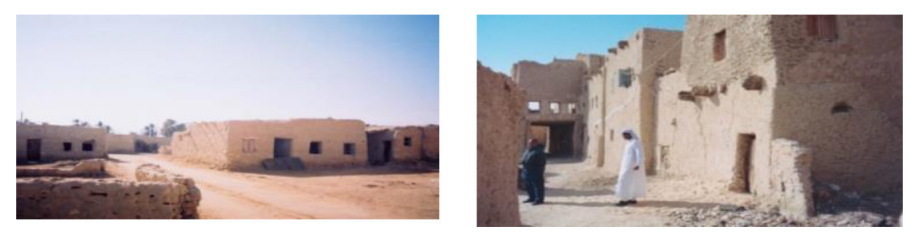

Figure 6: Types of houses and residential units in Siwa [12].

Table1: Goals of proceeding with the subject-based main items of sustainable design.

\begin{tabular}{|c|c|}
\hline Aims & Items \\
\hline $\begin{array}{l}\text { Practical } \\
\text { (Form + Activity) }\end{array}$ & $\begin{array}{l}\text {-Making special formal facilities in the Oasis for people and } \\
\text { tourists. } \\
\text {-Planning, arranging and reviewing formal patterns of the Oasis. } \\
\text {-Maintaining space, formal variety and available hierarchy in } \\
\text { Oasis architecture. } \\
\text {-Maintaining variety of functions and their respective usage. } \\
\text {-Orienting people and meeting their needs. } \\
\text {-Supporting social justice and creating an association for people of } \\
\text { the Oasis to help them. } \\
\text {-Making connections between old and new forms. } \\
\text {-Updating all missed forms and activities. } \\
\text {-Considering nature and native outlook of morphology. }\end{array}$ \\
\hline $\begin{array}{l}\text { Experimental, Aes- } \\
\text { thetic } \\
\text { (Activity + Visions) }\end{array}$ & $\begin{array}{l}\text { - Improving quality of host society. } \\
\text {-Maintaining solidarity and social integration and culture among } \\
\text { Oasis people. } \\
\text {-Maintaining consistency and emphasis to the identity of the Oasis } \\
\text { structure. } \\
\text {-Maintaining the cultural and social living values of Oasis people. } \\
\text {-Maintaining and concentrating on the native outlook and natural } \\
\text { environment } \\
\text {-Emphasizing natural forms based on visual items. } \\
\text {-Protecting, renovating and maintaining historical masterpieces. } \\
\text {-Protecting oasis structure. }\end{array}$ \\
\hline $\begin{array}{l}\text { Environmental } \\
(\text { Form + Ecology) }\end{array}$ & $\begin{array}{l}\text {-Maintaining local and environmental capacities } \\
\text {-Observing the proper use of natural and environmental resources } \\
\text {-Concentrating to the natural, environmental and native outlook of } \\
\text { the area considering ecological anthropology } \\
\text {-Reducing pollution } \\
\text {-Balancing ecologies }\end{array}$ \\
\hline
\end{tabular}

cover different and complex sustainable designs and can assume a wide range of items. Therefore, classifying the aims, guidelines and related measures to sustainable design with an approach to sustainable Ecotourism in Siwa Oasis has been attempted. The amount of efficiency of the model in case of universality is examined in Table 1 . These levels consist of strategies and measures, which will be discussed in Table 2, that provide programs and actions that are needed for research. The strategies mentioned in the research subject might 
Table 2: Strategies of proceeding with the subject based on main items of sustainable design.

\begin{tabular}{|c|c|}
\hline Strategies & Items \\
\hline $\begin{array}{l}\text { Practical } \\
\text { (Form + Activity) }\end{array}$ & $\begin{array}{l}\text {-Mixing different usages. } \\
\text {-Using practical design. } \\
\text {-Permeability of activities. } \\
\text {-Reviewing and supervising tasks by oasis people. } \\
\text {-Compatibility of shape and function. } \\
\text {-Space flexibility. } \\
\text {-Maintaining sequences of actions. } \\
\text {-Distinguishing and meeting society's needs. } \\
\text {-Optimization of land usage and density. } \\
\text {-Providing safety for different activities. } \\
\text {-Creating communities. }\end{array}$ \\
\hline $\begin{array}{l}\text { Experimental-Aesthetic } \\
\text { (Activity + Visions) }\end{array}$ & $\begin{array}{l}\text {-High quality activities and available spaces. } \\
\text {-Supporting social vitality. } \\
\text {-Difference between artificial shapes and natural organic shapes. } \\
\text {-Personalizing options. } \\
\text {-Increasing visual attractions of local oasis outlook. } \\
\text {-Natural and cultural heritage. } \\
\text {-Organizing and social meeting points (special and public places } \\
\text { in oasis). } \\
\text {-Increasing quality of oasis public and private places in different } \\
\text { seasons. } \\
\text {-Subjective role of oasis locations. } \\
\text {-Cultural meanings in local outlook of oasis (cultural outlook). }\end{array}$ \\
\hline $\begin{array}{l}\text { Environmental } \\
\text { (Form + Ecology) }\end{array}$ & $\begin{array}{l}\text {-Considering native relations of area (ecological anthropology) } \\
\text { and maintaining their balance. } \\
\text {-Considering efficiency of resources according to energy } \\
\text { stability. } \\
\text {-Minimizing environmental pollutions. } \\
\text {-Providing comfort for residents. } \\
\text {-Organizing designs compatible with nature and local outlook. } \\
\text { - Creating climate-compatible designs. }\end{array}$ \\
\hline
\end{tabular}
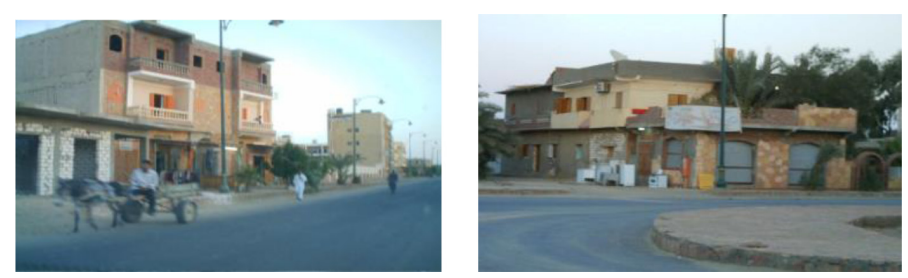

Figure 7: shows that the use of new types of finishing in Siwa led to distorting the ecological character of the Oasis(12) 
not have the necessary universality but classifying them to achieve a specific base will be efficient. Using compound strategy makes it possible to discuss all these strategies in a systematic format and maintaining an independent domain in every subject it also makes it possible to study relationship among them. Because every strategy has its specific strengths and weaknesses; nevertheless compound strategies use each other's benefits increasing their weakness points [11].

Accordingly, different aspects of two or more strategies (1 - Practical (Form + Activity) -2 Experimental-Aesthetic (Activity + Visions) - 3 Environmental (Form + Ecology), have been discussed in order to achieve sustainable design strategies in Siwa Oasis. A specific solution is introduced to create solidarity between two strategies (Practical (Form + Activity) -2 Experimental - Aesthetic (Activity + Visions), and will be handled in Table 3.

Table 3: Strategies for proceeding with the research subject.

\begin{tabular}{|c|c|}
\hline Strategies & Items \\
\hline $\begin{array}{l}\text { Practical } \\
\text { (Form +Activity) }\end{array}$ & $\begin{array}{l}\text {-Designing formal multipurpose spaces on different levels. } \\
\text {-Prioritizing solidarity, clarity, continuity and balance of activi- } \\
\text { ties in visual order. } \\
\text {-Providing suitable access and formal visual connection with } \\
\text { other locations in the Oasis. } \\
\text {-Giving Oasis people the right to participate in decision-making } \\
\text { and management. } \\
\text {-Allowing the use of public areas in the Oasis. } \\
\text {-Compatibility of the shape of the Oasis (new artificial forms) } \\
\text { with regards to the Oasis people's different forms of activity. } \\
\text {-Designing spaces with ability to support functions and different } \\
\text { activities. } \\
\text {-Flexibility of design to adapt with continuous changes. }\end{array}$ \\
\hline $\begin{array}{l}\text { Practical } \\
\text { (Form +Activity) }\end{array}$ & $\begin{array}{l}\text {-Increasing efficient capacity of fundamentals in taper-shaped } \\
\text { structures. } \\
\text {-Providing necessary facilities for safety in passageways, struc- } \\
\text { tures, and places. } \\
\text {-Adjusting spaces and places with specific Oasis' environment } \\
\text { standards. } \\
\text {-Controlling the Oasis skyline. } \\
\text {-Concentrating on the nature of locations before concentrating } \\
\text { on the quality of formal elements } \\
\text {-Learning from past and respecting the current structure of the } \\
\text { Oasis and renovating and protecting it in order to honor history. } \\
\text {-Observing creative relations in the behavior of Oasis locals. } \\
\text {-Providing necessary facilities to protect and increase native jobs } \\
\text { as well as supporting culture. } \\
\text {-Considering host's culture in design. } \\
\text {-Matching visual properties to functions. }\end{array}$ \\
\hline
\end{tabular}




\begin{tabular}{|c|c|}
\hline Strategies & Items \\
\hline $\begin{array}{l}\text { Experimental- } \\
\text { Aesthetic (Activity } \\
\text { + Visions) }\end{array}$ & $\begin{array}{l}\text {-Considering details of places. } \\
\text {-Attraction and clarification of activities and their purpose. } \\
\text {-Continuity, alternation and consistency of edges of artificial } \\
\text { shapes with organic shapes and using various shapes and visual } \\
\text { permeability. } \\
\text {-Consistency with nature in Oasis structure. } \\
\text {-Supervising construction assisted by Oasis people. } \\
\text {-Renovating structures and historic areas. } \\
\text {-Reviewing outlooks in public passageways according to } \\
\text { privacy. } \\
\text {-Designing a place to produce and sell Oasis artwork and } \\
\text { handcrafts. } \\
\text {-Selecting well-matched materials for decoration, and setting up } \\
\text { signs. } \\
\text {-Providing easy navigation to different parts of the Oasis. } \\
\text { - Designing sidewalks consistent with the climate. } \\
\text {-Using dominant wind for natural ventilation of public and } \\
\text { private places. } \\
\text {-Preventing high moisture inside structures. } \\
\text {-Reducing noises and using appropriate means for disposal. } \\
\text {-Designing energy saving buildings. } \\
\text {-Using ecological anthropology patterns of the area in design. } \\
\text {-Locating usages in order to maintain available natural } \\
\text { ecologies. }\end{array}$ \\
\hline
\end{tabular}

\section{CONCLUSION}

In this research, effective relation between a good design based on the rules of ecological anthropology, and the standard of living has been emphasized in a way that by implementing Oasis plans, the act of increasing physical quality of the environment leads to increasing people's standard of living. The natural landscape of Siwa has not been considered just as a formal component. Moreover, creating artificial spaces without attractions was not attempted. The subject of sustainable design and creating perfect and dynamic places in the Oasis according to social, cultural, economic, and formal-environmental elements have been strategic goals of increasing the standard of areas in the Oasis. Meanwhile, sustainable tourism springs from the necessity to reduce the side effects of tourism. So, the strategy to protect natural capacities of native outlooks in Siwa Oasis areas in addition to socio-economical form of the Oasis will attract tourists, help economic and cultural development, and provide opportunities for oasis people. This Oasis should be expanded in a way that the formation and evolution of its structure occur along a continuous development process. Gradual historical development is considered based on accepted patterns and rules of sustainable development that will lead to a systematic environment. It is necessary to note that forms of ecological anthropology of present spaces of Siwa affect social and cultural elements and their creation. There is no difference between form and function in an oasis environment, because the 
configuration stems from a job that you need the oasis environment; the visualized meaning of these spaces is affected by social and cultural forces.

\section{REFERENCES}

[1] Lea M.S. \& Stephen, D., Tourism indigenous and local communities and protected areas In Developing Nations - Tourism And Protected Areas, Benefits Beyond Boundaries: The Vth Iucn World.

[2] Akbari, S., Sustainable Development in Oasis, The Ninth Sharjah Urban Planning Symposium (SUPS9), Sharjah, UAE, 2006.

[3] Saleh, M. \& Eben, A., A transformation in the vernacular landscape: assessing the aesthetic quality of Al-Khalaf Oasis, southwestern Saudi Arabia. Building and Environment, 36, 2002.

[4] Yencken, D. \& Williamson, D., Resting the Compass: Australia's Journey towards Sustainability, CSIRO Publishing: Melbourne, 2001.

[5] Tourism in Marine Environments, Vol 5(2-3), 2009, Cognizant Communication Corporation, p. 84.

[6] Neil Moisey Stephen, R. \& McCool,F., Tourism, Recreation, and Sustainability: Linking Culture and the Environment, the British Library, London, p. 56.

[7] El-Demery, A., Siwa between the Present and the Past, Alexandria, 2005.

[8] Ritchie, A. \& Thomas, R., Sustainable Urban Design: An Environmental Approach, Taylor \& Francis: London and New York, 2006.

[9] General Organization for Physical Planning, Planning Center of Alexandria Region, Comprehensive Development Strategy of the Siwa Oasis, Egypt, 2006.

[10] Golkar, K., Constructive components of the urban design quality, Soffeh magazine, 11th year, spring and summer, Vol. 32, Tehran, 2005.

[11] Groot, L. \& David,W., Research methods in architecture, translated by Alireza Eynifar, Published in Tehran University, Tehran, 2005.

[12] Tolba, M., Strengths and weaknesses in the assessment of sustainable tourism - a case study of nabq protected area in Egypt. WIT Transactions on Ecology and the Environment, 187, 2012, ISSN 174-3541, doi.10.2495/AIR 120101 